\title{
Toxicology of Ngirimbo: Analysis to Determine the Levels of Trace and Heavy Metals, Moisture, Nicotine, pH and Microbial Assessment.
}

Vita Mithi ( $\sim$ vitavmithi@gmail.com )

Armref Data for Action in Public Health Research https://orcid.org/0000-0002-4805-7335

Happy Matchabani Mhango

Malawi Bureau of Standards

Getrude Boti Phiri

Malawi Bureau of Standards

Rebecca S. Dewey

University of Nottingham

Research

Keywords: Cancer, Herbal, Health hazard, Ngirimbo, Nicotine replacement, Smokeless tobacco, Toxic

Posted Date: November 5th, 2021

DOI: https://doi.org/10.21203/rs.3.rs-1006502/v1

License: (a) (i) This work is licensed under a Creative Commons Attribution 4.0 International License.

Read Full License 


\section{Abstract}

Introduction: Tobacco and other similar/related products represent a substantial proportion of recreationally-used substances in Malawi. Ngirimbo is a smokeless substance taken orally to reduce tobacco smoking. This study aimed to determine the toxicological characteristics of Ngirimbo in terms of pesticide residues, microbial, trace and heavy metal contaminants, herbal compounds, and nicotine, moisture, and pH levels.

Methods: Samples were analysed using atomic absorption spectrophotometry, titration, X-ray fluorescence spectroscopy, UV-visible Spectrophotometer, gas chromatography-mass spectrometry, $\mathrm{pH}$ and gravimetric analysis, ISO4833, ISO21527, ISO16654, and ISO6579.

Results: From a total of 12 samples, 5 samples contained nicotine ranging from $0.08-0.84 \%$, while the remaining 7 samples showed no trace of nicotine. Sample pH ranged from 6.68 to 8.32, and moisture content from $12.87-47.11 \%$. Samples had no detectable contamination with chlorine or pesticide residue. Heavy metals tested: Cadmium, Nickel, Lead, and Copper were found to be below the detection limit of $0.01 \mathrm{mg} / \mathrm{kg}$. On the other hand, X-ray fluorescence spectroscopy analysis revealed the presence of Nickel, Bromine, Rubidium, Strontium, Zirconium, Molybdenum, Rhodium, Cadmium, Chromium, and Tellurium. Samples had good levels of Calcium, Iron, Potassium, Sodium, and Zinc ranging from $23 \mathrm{mg} / \mathrm{kg}$ to $57,800 \mathrm{mg} / \mathrm{kg}$. Samples contained phytocompounds and herbal material of medicinal relevance. In terms of the microbiological content, Escherichia coli and Salmonella were absent, while Moulds and Yeast were present at a level of $<1 \mathrm{cfu} / \mathrm{g}$, with the total plate count varying across all samples between $1,400 \mathrm{cfu} / \mathrm{g}$ and 640,000 cfu/g.

Conclusion: These findings demonstrate that the current state of Ngirimbo available in Malawi is toxic and a hazard to human health.

Implications: Prolonged use of Ngirimbo may lead to users developing mouth cancers or thermal burns to the oral mucosal membrane. Further, Ngirimbo consumers are at risk of developing dental caries, known to harbour microorganisms and development of infectious diseases.

The control and regulation of Ngirimbo is highly recommended to maximise its capacity for use as a treatment/medication for tobacco replacement while minimising the negative impact on public health. Further work needs to be done to quantify the contents of Ngirimbo, and develop tolerance limits so that it may be used as a nicotine and tobacco replacement product.

\section{Introduction}

Tobacco and its interrelated products represent a significant proportion of recreationally-used substances, ${ }^{1}$. The use of natural products such as Ngirimbo remains a central part of sociocultural life as well as providing a way of reducing tobacco smoking and its harms among passive and active tobacco 
smokers in Malawi. People living in rural areas share and sell Ngirimbo, with the consequence of significantly reducing the interest in tobacco smoking, even among the youth of Malawi.

Although cigarette smokers still comprise the largest proportion of the tobacco using population making smoking the preferred route of tobacco intake, users of smokeless tobacco products (STPs) now account for $0.4 \%$, making their contribution significant, ${ }^{2}$. Well known STPs like nicotine replacement therapy (NRT), Varenicline, electronic cigarettes, and Snus, often combining medication and behavioural support, ${ }^{3}$, are not currently available in Malawi.

The 2019 World Health Organisation report on the global tobacco epidemic, suggested that $1.4 \%$ of the Malawian population currently uses smokeless tobacco, with $0.8 \%$ using it on daily basis, ${ }^{4}$. Furthermore, the report highlighted that there are currently no available forms of treatment for tobacco dependence available in Malawi, ${ }^{5}$. Consequently, smokers are driven to local alternatives such as Ngirimbo. According to the 2017 report on the Malawi National STEPwise Survey for Non-Communicable Diseases Risk Factors, tobacco use is increasingly becoming a significant cause of mental ill-health, morbidity, and mortality among adults and young people in Malawi, ${ }^{6}$.

The objective of this study was to carry out an analysis of Ngirimbo available in northern Malawi. The study aimed to estimate moisture and $\mathrm{pH}$ levels, and to quantify the heavy metal content which, in turn, was used to categorise the carcinogenic potential according to the International Agency for Research on Cancer (IARC) monographs. We hope this study will enable a consensus to be reached regarding the toxicity of Ngirimbo available locally and to motivate the authorities to take the necessary regulatory measures to control the sale and use of the product. As such, this study provides an exclusive report characterising the properties of Ngirimbo, while providing in-depth context in terms of the disproportionate burden of substance use borne by rural communities, and the potential for Ngirimbo to increase morbidity and decrease life expectancy.

\section{Materials And Methods}

\section{Sample collection and preparations}

Samples of Ngirimbo were collected from producers in twelve different areas of the Chitipa district of northern Malawi. Producers were selected based on popularity. Collected samples were stored in sealed glass jars in a cool storage room.

\section{Nicotine content analysis}

Each sample was dried in a drying oven (Carbolite Geno) at $105^{\circ} \mathrm{C}$ overnight. $0.120 \mathrm{~g}$ of each dried sample was then weighed into a $250 \mathrm{ml}$ conical flask. $150 \mathrm{ml}$ of $0.05 \mathrm{~N} \mathrm{HCl}$ solution was added together with approximately $0.2 \mathrm{~g}$ of activated charcoal. Flasks were then covered with watch glasses and the mixtures boiled for 5 minutes using a hot plate. After boiling, the contents were cooled to room temperature and transferred to $250 \mathrm{ml}$ volumetric flasks using $0.05 \mathrm{~N} \mathrm{HCl}$ for washing and making up to 
volume. The contents were then filtered slowly through Whatman No. 3 filter paper into $250 \mathrm{ml}$ conical flasks. Ultraviolet (UV) absorbance of the filtrates was then measured at the wavelengths 236, 259 and $282 \mathrm{~nm}$ using an Agilent 8453 UGV-Vis spectrophotometer calibrated prior to use. The absorbance obtained for each sample at each stated wavelength was then used to calculate the nicotine content of the sample.

\section{Measurement of pH}

$10.0 \mathrm{~g}$ of each powder was weighed in duplicate using a Mettler Toledo analytical balance and transferred into $100 \mathrm{ml}$ volumetric flask, mixed well and distilled water added to volume. The mixture was left to stand for a few minutes and the $\mathrm{pH}$ measured using a Hanna $\mathrm{pH}$ meter that had been previously calibrated using 4.01 and 10.01 buffer solutions.

\section{Trace metal and heavy metal content analysis}

$1.0 \mathrm{~g}$ of each sample was weighed in duplicate on a Mettler Toledo analytical balance before being placed into a Kjeldahl flask. To this, $30 \mathrm{ml}$ nitric acid and $20 \mathrm{ml}$ perchloric acid were added. The mixture was then heated on a heating mantle until it became clear before being allowed to cool down to room temperature. The mixture was then transferred quantitatively into a $250 \mathrm{ml}$ volumetric flask, and topped up to volume with distilled water. $1 \mathrm{ml}$ of the mixture was pipetted into a $100 \mathrm{ml}$ volumetric flask $10 \mathrm{ml}$ lanthanum chloride solution and was added before being topped up to the mark with distilled water. The resulting solution was analysed using an atomic absorption spectrophotometer (Analytik Jena) at the specified wavelength and the concentration recorded. Where further dilution of the sample was done, the dilution factor was taken into account in the calculations.

\section{Toxic substance analysis}

$10 \mathrm{~g}$ of each sample was weighed on a previously calibrated Mettler Toledo analytical balance and placed into an open-ended X-ray fluorescence (XRF) sample cup and covered using $6 \mu \mathrm{m}$ Mylar film. The sample cup was then placed into the XRF auto-sampler and covered well. The samples were analysed and the spectra recorded to provide a wide range of elements present in the samples.

\section{Chlorine content analysis}

$2 \mathrm{~g}$ of crystalline potassium iodide was dissolved in $50 \mathrm{ml}$ distilled water in a $250 \mathrm{ml}$ Erlenmeyer flask, and $10 \mathrm{ml}$ of acetic acid was added. To this mixture, $10 \mathrm{~g}$ of each sample was added and the mixture was stirred with a stirring rod for 10 minutes. The mixture was then immediately titrated with $0.1 \mathrm{~N}$ sodium thiosulphate solution until the iodine colour was nearly gone. Then $1 \mathrm{ml}$ of starch indicator solution was added and titration was completed until the blue colour disappeared. A control (blank) sample was also processed in the same manner described. Titre volumes for each sample and for the blank were used for the calculation of the chlorine content.

\section{Moisture content analysis}


Moisture content analysis was conducted using the oven drying method. A container with a lid was weighed using a Mettler Toledo analytical balance that had previously been calibrated prior to use and its mass recorded. The analytical balance was tared and $1 \mathrm{~g}$ of each sample was weighed and its initial mass recorded. The container was immediately sealed with its lid to avoid introducing atmospheric moisture into the sample. The weighed sample was then dried in a thermostatically controlled drying oven (Carbolite Geno) at $105^{\circ} \mathrm{C}$ for 24 hours. After 24 hours, the container was placed in a desiccator to cool for two hours and the container together with the sample was weighed and its mass recorded. Finally, the mass of moisture lost on drying was calculated using the masses recorded.

\section{Pesticide residue analysis}

Approximately $1.0 \mathrm{~g}$ of each sample was weighed in a $50-\mathrm{mL}$ polypropylene tube. $10 \mathrm{ml}$ Milli-Q ultrapure water were added to the sample, and allowed to sit for 30 minutes. $10 \mathrm{ml}$ of acetonitrile were then added as an extraction solvent and the mixture was thoroughly shaken for 1 minute, before being stored for 10 minutes at $-18^{\circ} \mathrm{C}$. Agilent Bond Elut QuEChERS extraction salts were then added to the mixture. The tube was closed tightly and shaken for 1 minute. Samples were centrifuged for 5 minutes at 5,000 rpm. One $\mathrm{ml}$ of the clear supernatant was diluted 10 times using the diluent before being filtered through a $0.45-\mu \mathrm{m}$ PTFE syringe filter. Analysis was conducted using an Agilent 1290 Infinity II coupled to an Agilent 6460 Triple Quadrupole LC/MS/MS and an Agilent GC system 7890A coupled with Agilent 5975C MSD.

\section{Herbal material analysis}

$1.0 \mathrm{~g}$ of each sample was weighed in a 50-mL polypropylene tube and extracted with hexane for 48 hours at a temperature between 60 and $65^{\circ} \mathrm{C}$ using a Soxhlet extractor. Repeated extraction was conducted using the same solvent until a clear colourless solution was obtained. This extract was evaporated using nitrogen until dry. The residue was then reconstituted using hexane, filtered through $0.45-\mu \mathrm{m}$ PTFE syringe filter, and placed in a vial for analysis. Analysis was conducted using an Agilent GC system 7890A coupled with an Agilent 5975C MSD and Chemstation software.

\section{Microbial analysis}

Each sample was subjected to microbial analysis to assess for total aerobic count, moulds and east, Escherichia coli, and Salmonella. All analyses were conducted in accordance with the International Organisation for Standardization (ISO) standards. Media were verified for specificity and pH prior to use. All equipment used in this analysis was calibrated by Accredited Laboratories: Archimedes Laboratory Solutions and Malawi Bureau of Standards; Metrology Services Department.

Total aerobic plate count: This was conducted in accordance with ISO 4833-1: using the pour plate technique with Plate Count Agar. $10 \mathrm{~g}$ of each sample was weighed, and $90 \mathrm{ml}$ of peptone water (diluent) was added to make the first dilution (10-1). $1 \mathrm{ml}$ of this mixture was then transferred from into $9 \mathrm{ml}$ of diluent to make the second dilution, and thereafter serial dilutions were made up to $\left(10^{-4}\right) .1 \mathrm{ml}$ of each dilution was then transferred into $90 \mathrm{~mm}$ petri dishes in duplicate. The prepared medium was then poured into the petri dishes and left to solidify. The plates were then incubated at $30 \pm 1^{\circ} \mathrm{C}$ for 24 - 48 hours. 
Moulds and yeast: ISO 21527-2:2008 was followed using the pour plate technique with malt extract agar. $10 \mathrm{~g}$ of each sample was weighted and added to $90 \mathrm{ml}$ peptone water (diluent) to make the first dilution $\left(10^{-1}\right) .1 \mathrm{ml}$ of this dilution was then transferred into $9 \mathrm{ml}$ of diluent to make the second dilution $\left(10^{-2}\right)$ and thereafter serial dilutions were made up to $\left(10^{-4}\right) .1 \mathrm{ml}$ was then transferred from each dilution into $90 \mathrm{~mm}$ petri dishes in duplicate. The prepared medium was poured into the petri dishes and left to solidify. The plates were then incubated at $25 \pm 1^{\circ} \mathrm{C}$ for 5 to 7 days.

Escherichia coli: This was conducted following IS016654 and ISO 16649-2:2001 using the pour plate technique with Tryptone bile glucuronic medium (TBX). Duplicate plates of media were inoculated with each sample and or initial suspension. Decimal dilutions of the sample were inoculated in duplicates. The petri dishes were then incubated at $44 \pm 1^{\circ} \mathrm{C}$ for 18 to 24 hours.

Salmonella: Test was done in-accordance with ISO 6579- 1:2017 (Amd 1: 2020) using the presumptive technique with buffered peptone water, tetrathionate broth, McConkey agar, brilliant green agar, and XLD agar. $25 \mathrm{~g}$ of each sample was weighed and added to $225 \mathrm{ml}$ of buffered peptone water (pre-enrichment media), and incubated at $37 \pm 1^{\circ} \mathrm{C}$ for 24 hours. Then, $1 \mathrm{ml}$ was drawn from the mixture and placed into $10 \mathrm{ml}$ tetrathionate broth (enrichment media) and incubated at $37 \pm 1^{\circ} \mathrm{C}$ for 24 hours. Sub-culturing was then conducted using the solid media of McConkey Agar, XLD agar, and brilliant green agar and incubated at $37 \pm 1^{\circ} \mathrm{C}$ for 24 hours.

\section{Results}

\section{Nicotine content}

Nicotine was found in samples AY5681, AY5682, AY5685, AY5686, and AY5687 in concentrations varying from $0.08-0.84 \%$. All other samples contained no detectable nicotine (Figure 1 ).

\section{$\mathrm{pH}$ and moisture content}

As shown in Figure 2, the pH levels of the samples ranged from 6.68 to 8.32 with a mean $\mathrm{pH}$ of 7.5. The $\mathrm{pH}$ and moisture content are important aspects affecting nicotine delivery to the subcutaneous tissue of the mouth. Moisture content varied among the samples ranging between $12.87 \%$ and $47.11 \%$.

\section{Microbial Content}

Escherichia coli and salmonella were absent from all samples. Escherichia coli and salmonella are pathogenic bacteria that only need a small quantity of bacteria to be present in the food to cause food poisoning. There were no mould or yeast colonies, signifying a level of $<1 \mathrm{cfu} / \mathrm{g}$. The total aerobic plate count for the samples was found to range from $1,400 \mathrm{cfu} / \mathrm{g}$ to $640,000 \mathrm{cfu} / \mathrm{g}$, with sample AY 5685 having the highest value and sample AY5683 having the lowest (Table 1).

\section{Elemental mineral and heavy metal concentrations}


Levels of cadmium, nickel, lead and copper were below detectable levels, although XRF shows intense peak levels of availability. These heavy metal elements are categorised as carcinogenic by the International Agency for Research on Cancer (IARC). On the other hand, the product sample contains essential minerals (Iron, Potassium, Calcium, Zinc and Sodium) in higher amounts.

\section{Toxic Substances}

Analyses showed that the samples contained elements that are corrosive, flammable, toxic, carcinogenic, and damaging to health (Table 3).

\section{Pesticides residue, chlorine and herbal material}

Samples were not contaminated with chlorine or pesticide residues. However, samples contained a wide range of organic compounds or herbal materials as shown in Table 4.

\section{Discussion}

Chemically, Ngirimbo samples containing nicotine can be described as basic alkaloids, and this is the case for 5 out of the 12 samples (AY5681, AY5682, AY5685, AY5686, and AY5687). Nicotine is a highly addictive central nervous system stimulant, and is a highly pharmacologically active drug, causing ganglionic stimulation in low doses, and ganglionic blockage in high doses, ${ }^{7}$. Nicotine is very toxic and a hazard to human health, ${ }^{8}$. Conversely, the remaining 7 Ngirimbo samples contained no nicotine at all (AY5677, AY678, AY5679, AY5680, AY5683, AY5684, and AY5688), and as such could be described as herbal nicotine-free medicine. On this basis, they could be used for smoking cessation therapy as a nicotine and tobacco replacement product as they contain none of the nicotine found in cigarettes. However, the fact remains that nicotine and other herbal stimulants have the capacity to harm living organisms, ${ }^{9}$.

The mean $\mathrm{pH}$ of samples was greater than 7, as shown in Figure 2, which means that the product is basic in nature. The $\mathrm{pH}$ is an important determinant of the bioavailable proportion of any nicotine in the sample, and the absorption of carcinogens that can lead to higher levels of toxicity and greater risk of harm, ${ }^{10}$. Moisture is another major factor influencing nicotine absorption, ${ }^{1}$, with high moisture content increasing the absorption of nicotine or herbal drug and increasing the ease of consumption.

The microbial content of STPs is an important consideration for the protection of public health, ${ }^{11}$. The present analysis showed that some samples contained a high viable load of bacteria. Consumers of such a product would likely carry and/or consume pathogenic or opportunistic microorganisms, potentially causing an increase in infectious disease. By their very nature, smokeless products such as Ngirimbo are held between the gum and lips for a long period of time, further increasing the risk of oral mucosa contact and the release of microbial toxins, both of which are sufficient to create a public health concern. As such, the microbial content should be regulated by the Malawi Pharmacy, Medicines \& Poisons Board, and this is likely to require new regulation to cover STPS 
Minerals are inorganic elements or molecules that are needed by the body in trace amounts, typically between 1 and $2500 \mathrm{mg}$ per day, ${ }^{12}$. In nutrition, sodium, potassium, chloride, calcium, phosphate, sulphate, and magnesium are considered to be inorganic macronutrients, and iron, fluorine, copper, zinc, chromium, manganese, iodine, selenium, and molybdenum are trace minerals, because they are only needed in such minute quantities in the diet, ${ }^{13}$. The availability and consumption of the quantities these elements show in Tables 2 and 3 would likely lead to poisoning in humans. This signifies that mineral toxicity is a potential health risk for Ngirimbo consumers, and should be considered as a matter of concern. To fully understand this risk and thereby avoid mineral toxicity, ${ }^{14}$, it will be necessary to determine the levels of minerals ingested by Ngirimbo users and to consider the impact of this on mineral toxicity of consumers. It may be necessary and possible to reduce and refine the levels of minerals in the product over time.

Bromine, strontium, and rhodium are corrosive to human skin and can cause burns. The consumption of organic contaminants containing bromine can cause malfunctioning of the nervous system and genetic changes. Organic substances containing bromine can damage organs such as the liver, kidneys, and lungs, cause the stomach and gastrointestinal system to function, and also be carcinogenic. Strontium has been shown to cause musculoskeletal osteomalacia; a disease involving weight loss, decreased weight gain in development, or bone weaknesses. Rhodium consumption is associated with nephrotoxicity, characterised by a rapid deterioration in kidney function, ${ }^{15}$. Molybdenum is a vital trace element for humans, animals, and plants. In the human body, it is stored in the bones, glands, liver, and kidneys, and is used in the prevention of dental caries, treatment of anaemia and diabetes. It has been shown to enhance the function of the immune system, and is used as an anticancer agent, ${ }^{16}$. However, overexposure to molybdenum has been associated with reproductive fertility defects in humans, ${ }^{17}$. Exposures to compounds containing nickel, cadmium, and chromium-VI have been associated with an increased risk of lung cancer, even when exposures are below the occupational exposure limits. Exposures have also been associated with other cancers, ${ }^{18},{ }^{19}$. Zirconium has uses in molecular imaging in cancer patients, ${ }^{20}$, but animal studies have shown that zirconium compounds induce fibrosis and tumour formation, ${ }^{21}$. There is minimal information about Rubidium and Tellurium, with both being associated with effects on skin and eyes in humans and animals, ${ }^{22,23}$.

The World Health Organization (WHO) agency, IARC, have established a list of herbal materials (Table 4) that are potentially carcinogenic, ${ }^{24}$. Conversely, many herbs and their phytocompounds are gradually being acknowledged as providing complementary treatments for cancer. Clinical studies have reported beneficial effects of herbal medicines on survival, immunomodulation, and quality of life of cancer patients when used in combination with conventional therapeutics, ${ }^{25}$. However, their presence in Ngirimbo is likely only to be harmful and toxic.

\section{Conclusion}


In summary, the results of this analysis report varying levels of nicotine, minerals, and bacteria in Ngirimbo. Samples variously contained herbal material, phytocompounds, and toxic levels of trace elements. Although all samples were ostensibly made from the same plant (local tobacco), many of the samples contained no detectable trace of nicotine.

Consequently, Ngirimbo must be classified as a toxic drug and health hazard. The availability and actions of the constituent molecules and compounds found in Ngirimbo are ambivalent in nature, with impact on human health, as carcinogenic while, some may have the potential to treat cancer. Some compounds possess both properties simultaneously. While the incidence of cancer can be decreased by decreasing the rates of smoking tobacco, the consumption of smokeless tobacco, non-tobacco products (such as Ngirimbo), and other unapproved herbal medicines may in turn increase the risks of cancer and infectious diseases if not properly controlled and regulated. In the absence of any provision of recommended products for tobacco replacement or tobacco harm reduction, the indigenous community of Malawi has turned to Ngirimbo. Now, the health consequences of this consumption may create a new burden on society. The production and distribution of Ngirimbo needs to be regulated through comprehensive implementation and enforcement of the WHO Framework Convention on Tobacco Control, alongside the provision of more recommended smoking cessation products. Furthermore, there is need to outline guidelines for the recommended use of Ngirimbo.

Future research is needed to investigate the composition of samples that contained no nicotine, in terms of determining whether or not these samples contain tobacco, or some other plant. Furthermore, the present study had a narrow scope with regards to the number of bacterial species investigated. Moving forward, a broader experimental battery should be applied to identifying and examining the bacterial and microbial populations present in Ngirimbo and to evaluate the potential risks of exposure to these through Ngirimbo use. Much more investigation can be conducted into ascertaining how the product can be used and exploited as a herbal nicotine-free medicine or smokeless tobacco replacement product for smoking cessation.

\section{Abbreviations}

AAS Atomic Absorption Spectrophotometer

FCTC Framework Convention for Tobacco Control

GC-MS Gas chromatography-mass spectrometry

IARC International Agency for Research on Cancer

ISO International Organisation for Standardization

$\mathrm{pH} \quad$ Potential of hydrogen

STP Smokeless Tobacco Product 
WHO World Health Organisation

XRF X-ray fluorescence spectroscopy

\section{Declarations}

\section{Ethical Approval and Consent to participate}

Not applicable

\section{Availability of data and materials}

All raw and analysed data are available from the author upon request.

\section{Consent for publication}

Not applicable

\section{Competing interests}

No competing interests.

\section{Funding}

This study was funded by Knowledge Action Change. The funder did not take any part in designing the study, methods, collection, analysis and interpretation of data or in writing the manuscript.

\section{Authors' Contributions}

VM drafted the write up, HM and GP conducted sample analysis. RD, VM, HM and GP worked on language, drafts and content of the paper. VM worked on the discussion and reference. The final manuscript was read and approved by authors.

\section{Acknowledgments}

Thankful to God for his favour and grace of knowledge and wisdom to accomplish this research, we convey our gratitude to Knowledge Action Change (KAC), for funding this research through the Tobacco Harm Reduction Scholarship Programme. 
Special thanks to Malawi Bureau of Standards: Testing Services Department for the valuable technical support of sample Analysis.

Special thanks to Jon Derricott, Tobacco Harm Reduction Scholarship Manager, Knowledge Action Change; Dr. John Ramsey, retired analytical toxicologist; and Professor Rajesh N. Sharan, PhD., of NorthEastern Hill University, India, for guidance and mentorship throughout the research.

\section{Authors' information}

VM, Armref Data for Action in Public Health Research, Mbelwa road, Recreation Center, Mzuzu, Malawi

HM, Testing Services Department, Malawi Bureau of Standards, Moirs Road P.O Box 946 Blantyre Malawi GP, Testing Services Department, Malawi Bureau of Standards, Moirs Road P.O Box 946 Blantyre Malawi RD, Sir Peter Mansfield Imaging Centre, School of Physics and Astronomy, University of Nottingham.

\section{References}

1. Prabhakar V, Jayakrishnan G, Nair S V, Ranganathan B. Determination of Trace Metals, Moisture, pH and Assessment of Potential Toxicity of Selected Smokeless Tobacco Products. Indian J Pharm Sci. 2013;75(3):262-269. doi:10.4103/0250-474X.117398

2. Drope, Schluger, Cahn, Drope, Hamill, Islami, Liber, Nargis S. The Tobacco Atlas. Atlanta: American Cancer Society and Vital Strategies.; 2018. www.tobaccoatlas.org

3. Mcneill A, Brose L, Calder R, Hitchman S, Hajek P, McRobbie H. E-cigarettes: an evidence update. Public Heal Engl. Published online 2015:111.

4. World Health Organization. Country profile. Published online 2019:17-19. doi:10.1787/b0801bd1-en

5. World Health Organization. WHO Report on the Global Tobacco Epidemic, 2019.; 2019.

6. Ministry of Health Non-Communicable Diseases Risk Report. Published online 2017.

7. Macht DI, Davis ME. TOXICITY OF ALPHA- AND BETA-NICOTINES AND NORNICOTINES FOR LUPINUS ALBUS. Am J Bot. 1935;22(3):329-332. doi:https://doi.org/10.1002/j.15372197.1935.tb05022.x

8. National Center for Biotechnology Information. Compound Summary for CID 89594, Nicotine. Published 2021. Accessed September. 29, 2021.

https://pubchem.ncbi.nlm.nih.gov/compound/Nicotine..

9. Brunton, Laurence L, Björn C. Knollmann and RH-DG\& G. The Pharmacological Basis of Therapeutics, 13e. N.Y.: McGraw-Hill Education LLC.; 2018.

10. Sankhla B, Kachhwaha K, Hussain SY, Saxena S, Sireesha SK, Bhargava A. Genotoxic and Carcinogenic Effect of Gutkha: A Fast-growing Smokeless Tobacco. Addict Heal. 2018;10(1):52-63. doi:10.22122/ahj.v10i1.537 
11. Han J, Sanad YM, Deck J, et al. Bacterial Populations Associated with Smokeless Tobacco Products. Appl Environ Microbiol. 2016;82(20):6273-6283. doi:10.1128/AEM.01612-16

12. Soetan KO, Olaiya $\mathrm{CO}$, Oyewole OE. The importance of mineral elements for humans, domestic animals and plants : A review. African J Food Sci. 2010;4(May):200-222.

13. Renwick AG. Toxicology of Micronutrients: Adverse Effects and Uncertainty. J Nutr. 2006;136(2):493S-501S. doi:10.1093/jn/136.2.493S

14. Ceacero F, Landete-Castillejos T, Olguín A, et al. Avoiding Toxic Levels of Essential Minerals: A Forgotten Factor in Deer Diet Preferences. PLoS One. 2015;10(1):e0115814. https://doi.org/10.1371/journal.pone.0115814

15. DESOIZE B. Metals and Metal Compounds in Cancer Treatment. Anticancer Res. 2004;24(3A):15291544. https://ar.iiarjournals.org/content/24/3A/1529

16. Odularu AT, Ajibade PA, Mbese JZ. Impact of Molybdenum Compounds as Anticancer Agents. Casella L, ed. Bioinorg Chem Appl. 2019;2019:6416198. doi:10.1155/2019/6416198

17. National Center for BiotechnologyInformation. PubChem Compound Summary for CID 23932, Molybdenum. Published 2021. Accessed October 4, 2021. https://pubchem.ncbi.nlm.nih.gov/compound/Molybdenum.

18. Sciannameo V, Ricceri F, Soldati S, et al. Cancer mortality and exposure to nickel and chromium compounds in a cohort of Italian electroplaters. Am J Ind Med. 2019;62(2):99-110. doi:https://doi.org/10.1002/ajim.22941

19. International Agency for Research on Cancer. Monographs on the Evaluation of Carcinogenic Risks to Humans - Volume 89. Smokeless Tob Some Tobacco-specific N-Nitrosamines. 2007;89. http://monographs.iarc.fr/ENG/Monographs/vol89/mono89.pdf

20. van de Watering FCJ, Rijpkema M, Perk L, Brinkmann U, Oyen WJG, Boerman OC. Zirconium-89 Labeled Antibodies: A New Tool for Molecular Imaging in Cancer Patients. Haubner R, ed. Biomed Res Int. 2014;2014:203601. doi:10.1155/2014/203601

21. National Center for Biotechnology Information. PubChem Compound Summary for CID 23995, Zirconium. Published 2021. Accessed October 4, 2021. https://pubchem.ncbi.nlm.nih.gov/compound/Zirconium

22. National Center for Biotechnology Information. PubChem Compound Summary for CID 5357696, Rubidium. Published 2021. Accessed October 4, 2021. https://pubchem.ncbi.nlm.nih.gov/compound/Rubidium

23. National Center for Biotechnology Information. PubChem Compound Summary for CID 6327182, Tellurium. Accessed October 4, 2021. https://pubchem.ncbi.nlm.nih.gov/compound/Tellurium

24. IARC. International Agency for Research on Cancer larc Monographs on the Evaluation of Carcinogenic Risks To Humans. larc Monogr Eval Carcinog Risks To Humansarc Monogr Eval Carcinog Risks To Humans. 2002;96:i-ix+1-390. http://monographs.iarc.fr/ENG/Monographs/vol83/mono83-1.pdf 
25. Yin S-Y, Wei W-C, Jian F-Y, Yang N-S. Therapeutic applications of herbal medicines for cancer patients. Evid Based Complement Alternat Med. 2013;2013:302426. doi:10.1155/2013/302426

\section{Tables}

Due to technical limitations, table 1 to 4 is only available as a download in the Supplemental Files section.

Figures

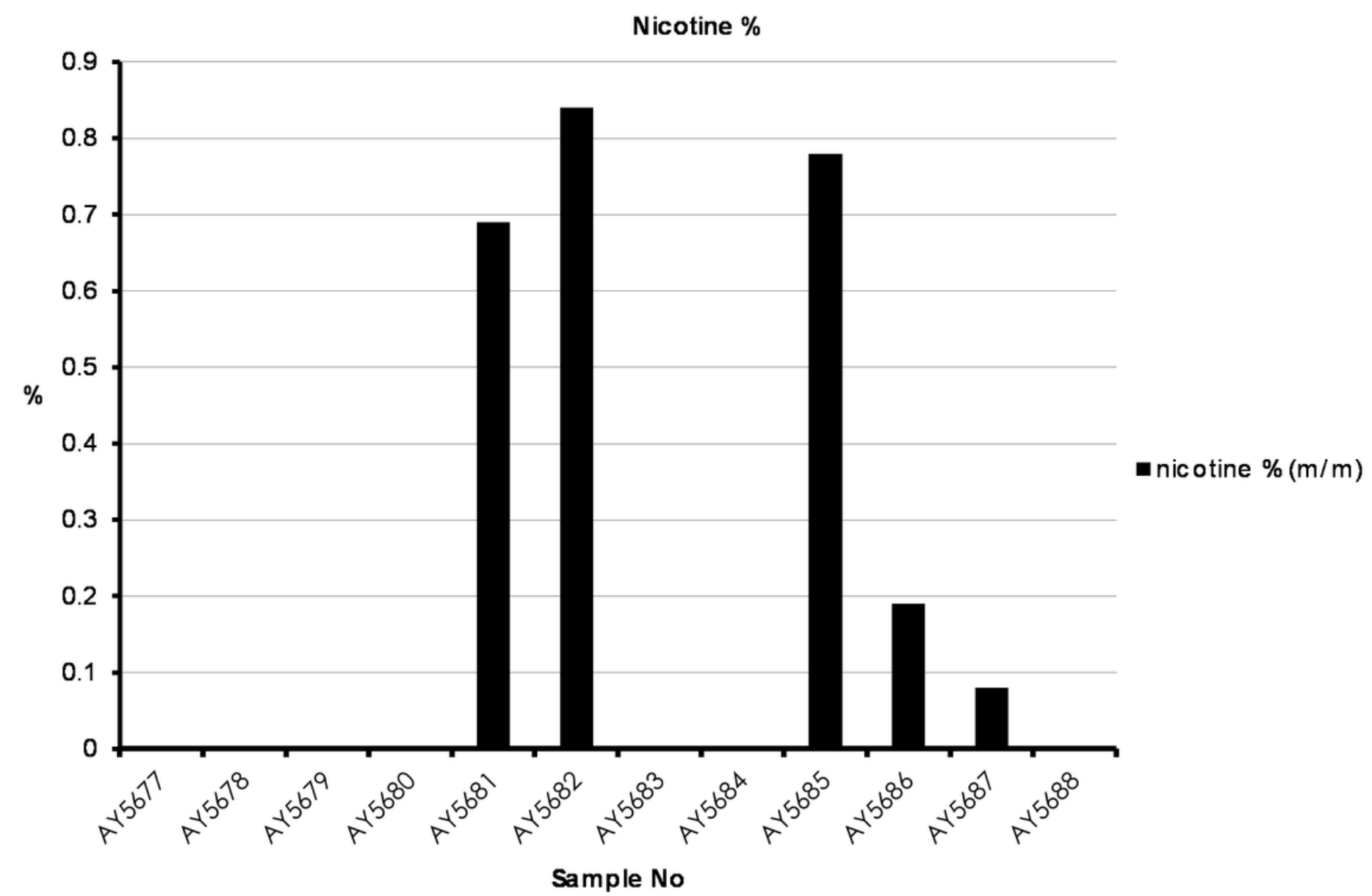

Figure 1

Nicotine content of each sample. 
$\mathrm{PH}$ and Moisture Content

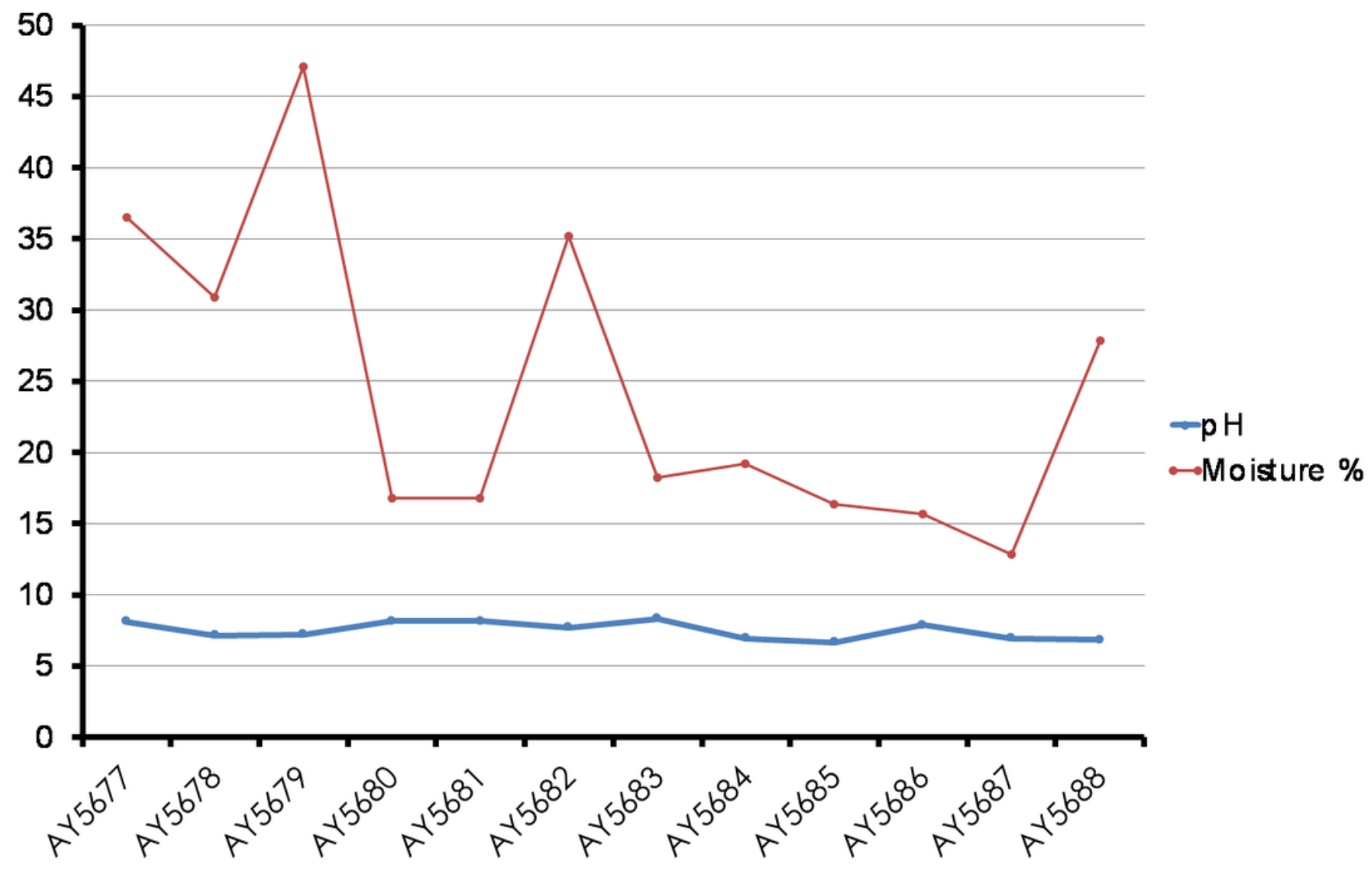

Sample No

$\mathrm{pH}$ of $10 \%$ solution

Moisture , \% m/m @ $105^{\circ} \mathrm{C}$

Figure 2

$\mathrm{pH}$ and moisture content of each sample.

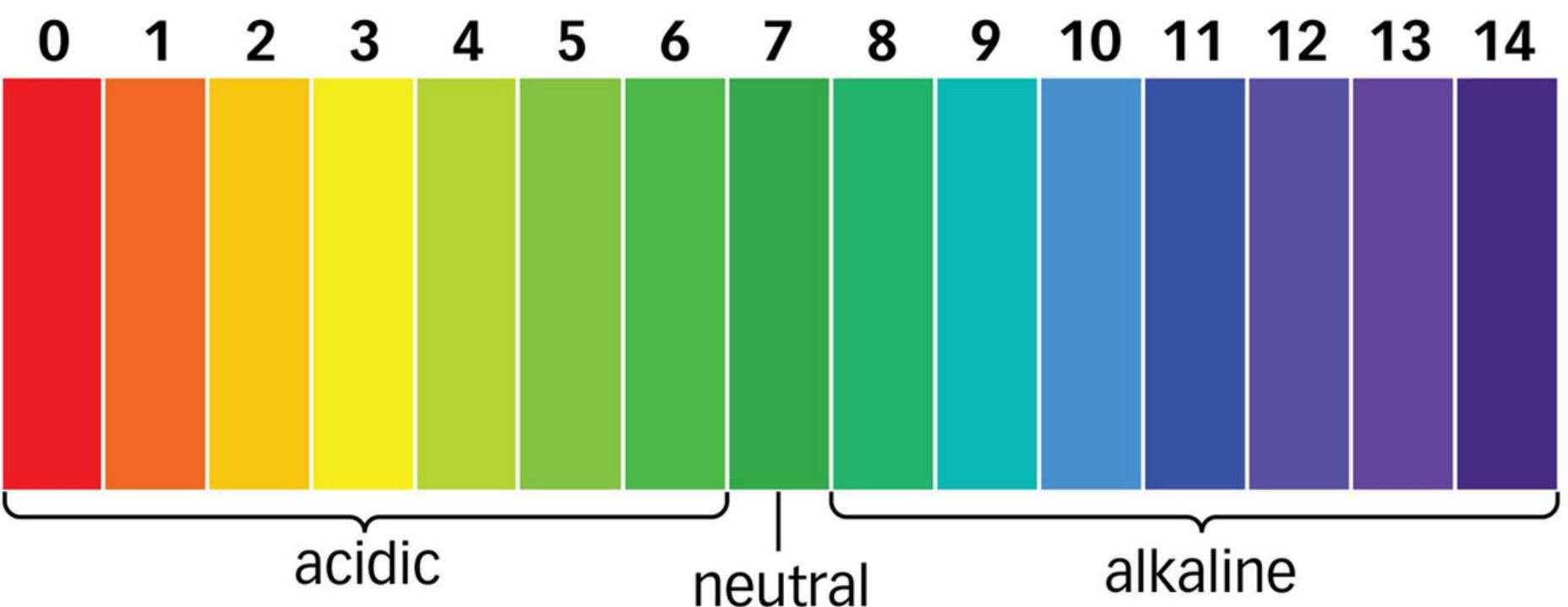


Figure 3

$\mathrm{pH}$ Indicator

\section{Supplementary Files}

This is a list of supplementary files associated with this preprint. Click to download.

- Tables.docx 